\title{
N. Momigliano et al. Settlement history and material culture in southwest Turkey: report on the 2008-2010 survey at Çaltılar Höyük (northern Lycia)
}

\section{Astrid Nunn}

\section{(2) OpenEdition \\ Journals}

Édition électronique

URL : http://journals.openedition.org/abstractairanica/41534

DOI : 10.4000/abstractairanica.41534

ISSN : 1961-960X

Éditeur :

CNRS (UMR 7528 Mondes iraniens et indiens), Éditions de l'IFRI

Référence électronique

Astrid Nunn, «N. Momigliano et al. Settlement history and material culture in southwest Turkey: report on the 2008-2010 survey at Çaltılar Höyük (northern Lycia) », Abstracta Iranica [En ligne], Volume 34-35-36 | 2017, document 19, mis en ligne le 15 juillet 2016, consulté le 02 octobre 2020. URL : http:// journals.openedition.org/abstractairanica/41534; DOI : https://doi.org/10.4000/abstractairanica. 41534

Ce document a été généré automatiquement le 2 octobre 2020.

Tous droits réservés 


\title{
N. Momigliano et al. Settlement history and material culture in southwest Turkey: report on the 2008-2010 survey at Çaltılar Höyük (northern Lycia)
}

\author{
Astrid Nunn
}

\section{RÉFÉRENCE}

N. Momigliano et al. « Settlement history and material culture in southwest Turkey: report on the 2008-2010 survey at Çaltılar Höyük (northern Lycia) ». Anatolian Studies, 61,2011 , p. 61-121.

1 Cet article présente les résultats des travaux effectués par la mission internationale au Çaltılar Höyük pendant les années 2008 à 2010. Ce site, situé dans le nord de la Lycie, resta densément habité du IV ${ }^{\mathrm{e}}$ mill. jusqu'à environ 550 av. J.-C. Cette date correspond à la conquête perse de la Lycie. Alors que la céramique grecque importée dès le VIII ${ }^{\mathrm{e}} \mathrm{s}$. provient de Corinthe et de l'Egée, la céramique à vernis noir provient de l'Attique à partir du $\mathrm{VI}^{\mathrm{e}} \mathrm{s}$. Cette céramique attique est toujours très importante car elle permet contrairement à la céramique locale - une datation beaucoup plus précise du contexte architectural. 


\section{AUTEURS}

\section{ASTRID NUNN}

Université de Munich 